\title{
Sequential Cdk1 and PIk1 phosphorylation of protein tyrosine phosphatase 1B promotes mitotic cell death
}

\author{
DS O'Donovan ${ }^{1}$, S MacFhearraigh ${ }^{1}$, J Whitfield ${ }^{2}$, LB Swigart ${ }^{2}$, GI Evan² and MM Mc Gee ${ }^{*, 1}$
}

Mitotic cell death following prolonged arrest is an important death mechanism that is not completely understood. This study shows that Protein Tyrosine Phosphatase 1B (PTP1B) undergoes phosphorylation during mitotic arrest induced by microtubuletargeting agents (MTAs) in chronic myeloid leukaemia cells. Inhibition of cyclin-dependent kinase 1 (Cdk1) or polo-like kinase 1 (Plk1) during mitosis prevents PTP1B phosphorylation, implicating these kinases in PTP1B phosphorylation. In support of this, Cdk1 and Plk1 co-immunoprecipitate with endogenous PTP1B from mitotic cells. In addition, active recombinant Cdk1-cyclin B1 directly phosphorylates PTP1B at serine 386 in a kinase assay. Recombinant Plk1 phosphorylates PTP1B on serine 286 and 393 in vitro, however, it requires a priming phosphorylation by Cdk1 at serine 386 highlighting a novel co-operation between Cdk1 and Plk1 in the regulation of PTP1B. Furthermore, overexpression of wild-type PTP1B induced mitotic cell death, which is potentiated by MTAs. Moreover, mutation of serine 286 abrogates the cell death induced by PTP1B, whereas mutation of serine 393 does not, highlighting the importance of serine 286 phosphorylation in the execution of mitotic cell death. Finally, phosphorylation on serine 286 enhanced PTP1B phosphatase activity. Collectively, these data reveal that PTP1B activity promotes mitotic cell death and is regulated by the co-operative action of Cdk1 and Plk1 during mitotic arrest.

Cell Death and Disease (2013) 4, e468; doi:10.1038/cddis.2012.208; published online 24 January 2013

Subject Category: Cancer

Mitotic catastrophe is an important oncosuppressive mechanism that senses mitotic failure and responds by driving the cell to an irreversible fate of death or senescence. ${ }^{1,2}$ Three types of mitotic catastrophe pathways have been described following aberrant mitosis, and include mitotic cell death induced in the presence of elevated cyclin B1, cell death in interphase following mitotic exit and finally, cell senescence. ${ }^{1,3}$ All types of mitotic catastrophe originate from mitotic perturbations and are accompanied by mitotic arrest; however, the molecular components that link prolonged mitosis to the cell death machinery remain largely unknown. ${ }^{4}$ Characterisation of the individual pathways of mitotic catastrophe will improve our understanding of cancer biology and uncover novel therapeutic targets.

Cyclin-dependent kinase 1 (Cdk1) and polo-like kinase 1 (Plk1) are the major mitotic serine/threonine kinases required for the timely progression through mitosis. Cdk1 forms a bipartite complex with cyclin $\mathrm{B} 1$ and regulates mitotic entry. Cdk1 is a proline-directed kinase that phosphorylates substrates at serine or threonine residues that immediately precede proline. ${ }^{5} \mathrm{Plk} 1$ co-ordinates a variety of cell division processes including centrosome maturation, recruitment of important mitotic spindle components and cytokinesis. ${ }^{6,7}$ Plk1 contains a regulatory polo box domain that has strong affinity for pSer-Pro and pThr-Pro motifs and controls localisation to substrates. ${ }^{8}$ Overexpression of Plk1 has a pro-survival role in tumourigenesis ${ }^{9,10}$ and its depletion leads to apoptosis. ${ }^{11,12}$ In contrast, contradictory reports highlight a tumour-suppressive role for Plk1 in certain tumours ${ }^{13,14}$ and phosphorylation by Plk1 induces the tumour-suppressive activity of FADD. ${ }^{15}$

Protein tyrosine phosphatase 1B (PTP1B) is a ubiquitously expressed member of the protein tyrosine phosphatase (PTP) superfamily that regulates protein phosphorylation status by antagonising tyrosine kinases. Thus, PTPs such as PTEN act as important tumour suppressors; however, more recently an oncogenic role has also been reported for some PTPs. ${ }^{16}$ PTP1B itself acts in a pro-apoptotic manner during cell death induced by serum starvation of immortalised neonatal hepatocytes and hypoxia/reoxygenation stress of rat cardiomyocytes. ${ }^{17,18}$ Furthermore, PTP1B suppresses STAT6 oncogenic activity ${ }^{19}$ and is a positive regulator of Bim transcription. ${ }^{20}$ Conversely, PTP1B is a positive regulator of src and ras signalling and is required for Her2/neu-induced neoplasia. ${ }^{21-23}$ Moreover, conflicting reports suggest that $\mathrm{PTP} 1 \mathrm{~B}$ is both a negative and positive regulator of the $\mathrm{Bcr}-\mathrm{Abl}$ oncogene in chronic myelogenous leukemia. ${ }^{24-26}$ Overall, these reports reveal a role for PTP1B in cell survival and cell death pathways. However, the precise function and regulation of PTP1B in tumourigenesis is poorly understood.

In this study we have identified PTP1B as a substrate for the co-ordinate phosphorylation by Cdk1 and Plk1 during mitotic arrest. Moreover, we have characterised the phosphorylation

${ }^{1}$ UCD School of Biomolecular and Biomedical Science, Conway Institute of Biomolecular and Biomedical Research, University College Dublin, Belfield, Dublin 4, Ireland and ${ }^{2}$ Department of Pathology and Helen Diller Family Comprehensive Cancer Center, University of California San Francisco, San Francisco, CA 94143, USA

${ }^{*}$ Corresponding author: MM Mc Gee, UCD School of Biomolecular and Biomedical Science, Conway Institute of Biomolecular and Biomedical Research, University College Dublin, Belfield, Dublin 4, Ireland. Tel: +00353 1716 6771; Fax: +00353 1716 6456; E-mail: Margaret.mcgee@ucd.ie

Keywords: mitosis; mitotic cell death; PTP1B; Cdk1; Plk1; mitotic catastrophe

Abbreviations: PTP, protein tyrosine phosphatase; PTP1B, protein tyrosine phosphatase IB; Cdk1, cyclin-dependent kinase 1; Plk1, polo-like kinase 1; CML, chronic myeloid leukaemia; PBD, polo box domain; MTA, Microtubule-targeting agent

Received 01.11.12; revised 09.11.12; accepted 12.11.12; Edited by RA Knight 
residues involved, and reveal that phosphorylation on serine 286 enhances PTP1B phosphatase activity and confers death promoting activity in CML cells. Thus, this study shows that the sustained phosphorylation of PTP1B by mitotic kinases during mitotic arrest promotes its tumour suppressor function and provides new insight into the molecular mechanism of mitotic catastrophe.

\section{Results}

PTP1B is localised at the ER and mitochondrion in CML cells and undergoes phosphorylation following treatment with Taxol and Nocodazole. Microtubule-targeting agents (MTAs) such as Nocodazole or Taxol induce mitotic catastrophe, following protracted mitotic arrest that ultimately leads to death of tumour cells, which is often associated with the intrinsic pathway. ${ }^{27,28}$ DiGE analysis of protein alterations during mitotic arrest induced by Nocodazole or Taxol in K562 cells revealed the altered abundance of full-length PTP1B at the mitochondria (data not shown). Herein, it is shown that PTP1B undergoes a dose- and time-dependent phosphorylation upon MTA treatment, which is apparent by a shift in protein mobility (Figures 1a and b). PTP1B phosphorylation correlates with the accumulation of cells in G2/M phase of the cell cycle and precedes the induction of death induced by Nocodazole and Taxol (Figure 1c). a
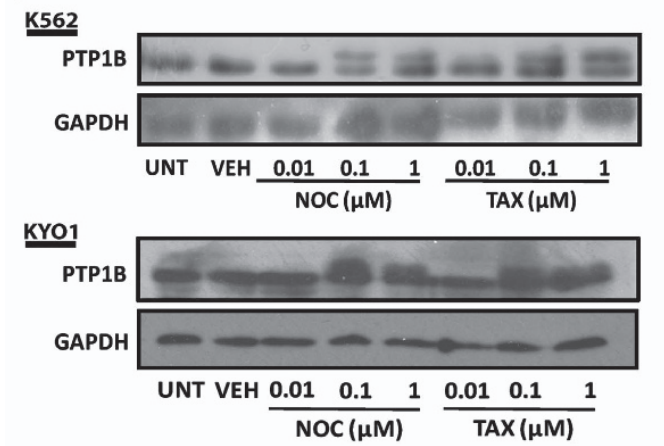

b

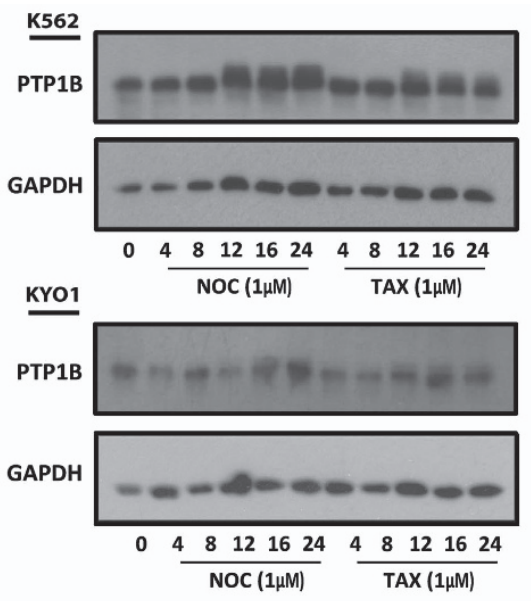

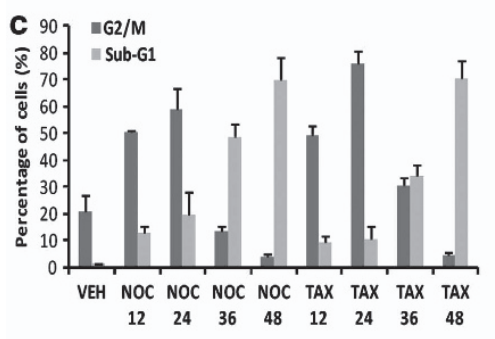

d

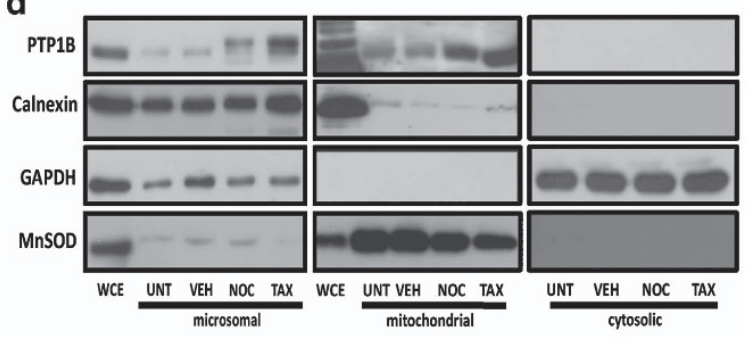

e
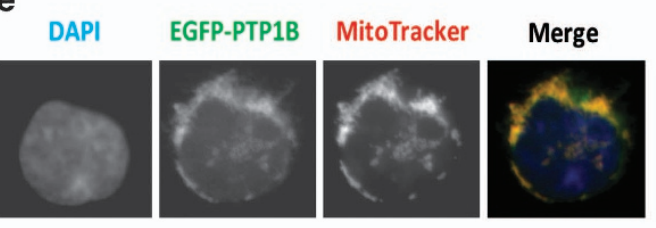

f

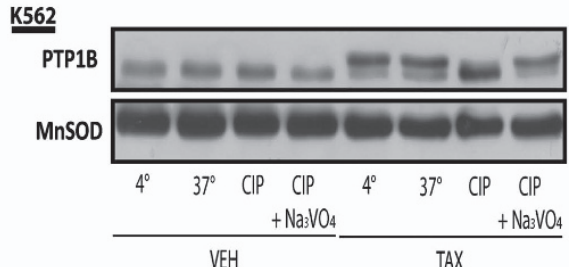

Figure 1 PTP1B undergoes phosphorylation during mitotic arrest induced by Taxol (TAX) and Nocodazole (NOC). K562 and KYO1 cells were untreated (UNT), treated with DMSO $(0.1 \% \mathrm{v} / \mathrm{v} ; \mathrm{VEH})$ and (a) increasing concentrations of NOC and TAX $(0.01-1 \mu \mathrm{M})$ for $12 \mathrm{~h}$ or $(\mathbf{b}) \mathrm{NOC}(1 \mu \mathrm{M})$ and TAX $(1 \mu \mathrm{M})$ for the indicated time points. Wholecell extracts (WCEs) were prepared and equal amounts of protein were resolved by SDS-PAGE and probed with anti-PTP1B antibody and anti-GAPDH antibody was used as a loading control. (c) K562 cells were treated with DMSO $(0.1 \% \mathrm{v} / \mathrm{v})$, NOC $(1 \mu \mathrm{M})$ or TAX $(1 \mu \mathrm{M})$ for $12,24,36$ and $48 \mathrm{~h}$. DNA content was analysed by flow cytometry following propidium iodide $(1 \mu \mathrm{g} / \mathrm{ml})$ staining and the percentage of cells containing $4 \mathrm{n}$ and $<2 \mathrm{n}$ DNA was calculated. (d) $\mathrm{K} 562$ cells were either left UNT or treated with DMSO (0.1\% $\mathrm{v} / \mathrm{v})$, NOC $(1 \mu \mathrm{M})$ or TAX $(1 \mu \mathrm{M})$ for $12 \mathrm{~h}$. Ultracentrifugation was used to separate mitochondrial, microsomal, and cytosolic fractions, and a WCE was retained as a control. Equal amounts of protein were resolved by SDS-PAGE, and probed with anti-PTP1B antibody by western blotting. Anti-calnexin, anti-GAPDH and anti-MnSOD antibodies were used as a microsomal, cytosolic and mitochondrial markers, respectively. (e) K562 cells were transfected with pEGFP-c1-PTP1B $(1 \mu \mathrm{g})$ and incubated at $37^{\circ} \mathrm{C}$ for $24 \mathrm{~h}$ prior to staining with DAPI $(1 \mu \mathrm{g} / \mathrm{ml})$ and MitoTracker $(100 \mathrm{nM})$, and images were acquired by fluorescent microscopy. (f) K562 cells were treated either DMSO $(0.1 \% \mathrm{v} / \mathrm{v})$ or TAX $(1 \mu \mathrm{M})$ for $12 \mathrm{~h}$. Mitochondrial protein $(50 \mu \mathrm{g})$ was incubated with CIP for $30 \mathrm{~min}$ at $37^{\circ} \mathrm{C}$, in the absence or presence of the $\mathrm{Na}_{3} \mathrm{VO}_{4}$. Protein was resolved by SDS-PAGE and probed with anti-PTP1B antibody. Anti-MnSOD antibody was used as a mitochondrial loading control 
The subcellular localisation of PTP1B was examined in $\mathrm{CML}$ cells. Mitochondrial, microsomal and cytosolic protein was isolated by subcellular fractionation and subjected to SDS-PAGE and western blot analysis. Results show that fulllength PTP1B is localised to the ER and mitochondria in K562 cells, but is absent from the cytosol (Figure 1d). ER localisation of PTP1B has been previously reported in mammalian cells, ${ }^{29}$ however, mitochondrial localisation is only reported in rat brain. ${ }^{30}$ The absence of the calnexin from the mitochondrial fractions highlights the purity of the fractions. Furthermore, the mitochondrial localisation of PTP1B was confirmed by co-localisation of exogenously expressed EGFP-PTP1B and MitoTracker Fluor in K562 cells (Figure 1e). Thus, we report that in addition to the ER, PTP1B resides at the mitochondrion in mammalian cells.

Finally, to confirm that the shift in mobility observed in PTP1B was due to phosphorylation, mitochondrial protein was isolated from $\mathrm{K} 562$ cells following treatment with either vehicle (DMSO $(0.1 \% \mathrm{v} / \mathrm{v}))$ or Taxol $(1 \mu \mathrm{M})$ for $12 \mathrm{~h}$, and incubated with calf intestinal phosphatase (CIP). The phosphatase reaction was carried out at $37^{\circ} \mathrm{C}$ in the absence or presence of the phosphatase inhibitor, $\mathrm{Na}_{3} \mathrm{VO}_{4}$. It was found that CIP completely inhibited the mobility shift of PTP1B induced by Taxol treatment, which was blocked by $\mathrm{Na}_{3} \mathrm{VO}_{4}$, confirming that mitochondrial PTP1B undergoes phosphorylation following MTA treatment (Figure 1f).

PTP1B phosphorylation is blocked by BI2536 and RO3306 treatment during mitosis. Cells were synchronised at the G1/S border using a double thymidine block and treated with Taxol $(1 \mu \mathrm{M})$ to allow accumulation in mitosis. At the indicated times, cells were treated with BI2536 $(1 \mu \mathrm{M})$, CK2 inhibitor $(20 \mu \mathrm{M})$ and RO-3306 $(9 \mu \mathrm{M})$ for $2 \mathrm{~h}$, to specifically inhibit Plk1, casein kinase 2 and Cdk1, respectively, and the effect on PTP1B phosphorylation was investigated. Phosphorylation of BubR1 is an early event during mitosis. ${ }^{31}$ Consistent with this, BI2536 blocked BubR1 phosphorylation when added 10 or $11 \mathrm{~h}$ post-thymidine release, which indicates early mitosis. However, BI2536 did not prevent BubR1 phosphorylation when tested $12 \mathrm{~h}$ post-thymidine release, revealing that BubR1 phosphorylation had already taken place. In addition, RO-3306 prevents the phosphorylation of Bim and BubR1 at 10 and $11 \mathrm{~h}$, as previously described. ${ }^{28,31}$ Inhibition of Plk1 or Cdk1 using these inhibitors blocks the phosphorylation of PTP1B during mitotic arrest, whereas inhibition of casein kinase 2 does not (Figure 2a). Collectively, these data implicate Cdk1 and Plk1 as potential PTP1B kinases.

Cdk1/cyclin B directly interacts with PTP1B and phosphorylates it on serine 386. A potential role for Cdk1 in the phosphorylation of PTP1B was investigated directly by coimmunoprecipitation and kinase assays. Firstly, endogenous PTP1B was immunoprecipitated from cell lysates prepared from interphase and mitotic K562 cells and examined for the presence of Cdk1 by western blot. It was found that Cdk1 coimmunoprecipitates with PTP1B in mitotic cells, however, not in interphase cells (Figure $2 b$ ). In each case, a portion of the K562 lysate (10\%) was retained and probed for PTP1B to confirm immunoprecipitation. This data demonstrates that
Cdk1 and PTP1B specifically interact in mitotically arrested cells. Next, an in vitro kinase assay was performed, whereby purified PTP1B was incubated with increasing concentrations of recombinant Cdk1/cyclin B1 $(0,110,230,460 \mathrm{ng})$ for $1 \mathrm{~h}$ at $30^{\circ} \mathrm{C}$ in the presence of ATP $(100 \mu \mathrm{M})$ and $2 \mu \mathrm{Ci}$ of $\left[\gamma-{ }^{32} \mathrm{P}\right]$ ATP. The reaction was terminated and proteins were resolved by SDS-PAGE and visualised by Coomassie Brilliant blue (CBB) staining. Analysis of $\gamma-{ }^{32} \mathrm{P}$ incorporation revealed that $\mathrm{PTP} 1 \mathrm{~B}$ is phosphorylated by recombinant Cdk1/cyclin B1 in a dose-dependent manner (Figure 2c).

PTP1B contains a putative proline-directed phosphorylation site at serine 386. A kinase assay was performed using two PTP1B mutants, S386A and S386E, generated by site-directed mutagenesis. Specifically, the active recombi-

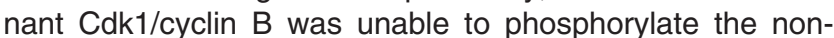
phosphorylatable S386A mutant or the phosphomimetic S386E mutant (Figure 2d). Furthermore, PTP1B contains a cyclin-binding domain RILEP at residues 315-319, which acts as a docking site for cyclin binding. Mutation of L317 within the cyclin-binding motif to L317G abolished the phosphorylation of PTP1B (Figure 2d). Normalised values are presented in Figure 2e. Collectively, this data reveals that cyclin binding to PTP1B facilitates its direct phosphorylation by Cdk1 on serine 386 .

PIk1 phosphorylates PTP1B, following a priming phosphorylation by Cdk1. The Plk1 inhibitor BI2536 blocked PTP1B phosphorylation in K562 cells, therefore, its candidature as a novel Plk1 substrate was investigated. PTP1B was immunoprecipitated from mitotically-synchronised K562 cell lysates as before and immunoprecipitated protein was resolved by SDS-PAGE and probed for Plk1. Results in Figure $3 a$ highlight that Plk1 co-immunoprecipitates with endogenous PTP1B in mitotic K562 lysates. A reverse immunoprecipitation was performed and PTP1B was found to co-immunoprecipitate with Plk1 from mitotic K562 cells (Figure 3b). In both cases, $10 \%$ of immunoprecipitated lysates were used to confirm the immunoprecipitation of PTP1B and PIk1, respectively.

Next, the ability to Plk1 to directly phosphorylate PTP1B in vitro was examined. PTP1B was incubated in a kinase assay with increasing concentrations of recombinant Plk1 for $1 \mathrm{~h}$ at $30{ }^{\circ} \mathrm{C}$ as before. However, in contrast to Cdk1, Plk1 did not phosphorylate wild-type (WT) PTP1B in vitro. CBB staining was used to confirm the presence of Plk1 and PTP1B in the reaction tubes (Figure $3 \mathrm{c}$ ). As a positive control, recombinant Plk1 was found to readily phosphorylate Cdc25C in vitro (Figure 3c). Thus, this data suggests two possibilities. The first is that Plk1 does not directly phosphorylate PTP1B. Alternatively, Plk1 may require a priming reaction to facilitate PTP1B binding and phosphorylation. Based on the finding that PTP1B and Plk1 co-immunoprecipitate in CML lysates, and that Cdk1 binds to and phosphorylates PTP1B, together with literature reports that Cdk1 cooperates with Plk1 to phosphorylate substrates, ${ }^{31-35}$ the latter hypothesis was favoured.

To test this possibility a two-step kinase assay was set up as outlined in Figure 3d, whereby purified PTP1B was incubated with either Cdk1 or Plk1 for $1 \mathrm{~h}$ in the presence of cold ATP. The kinase was heat inactivated and the substrate was co-incubated with either Plk1 or Cdk1 in a second kinase reaction. Protein was resolved by SDS-PAGE and visualised 
a

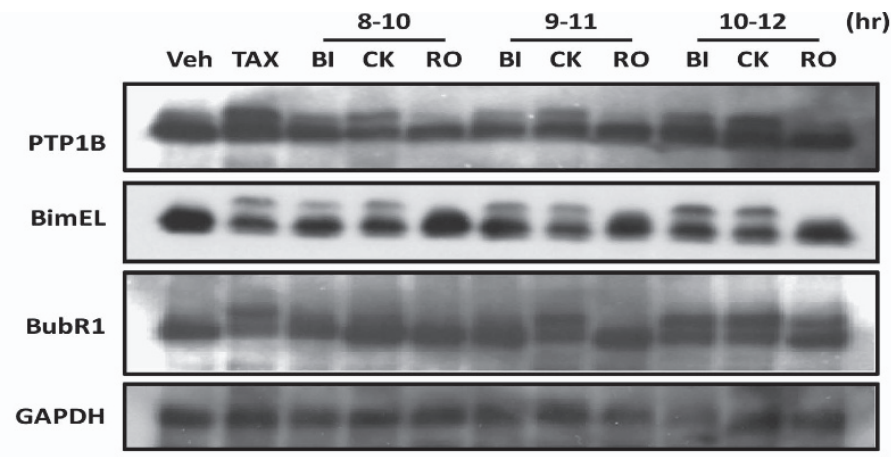

b
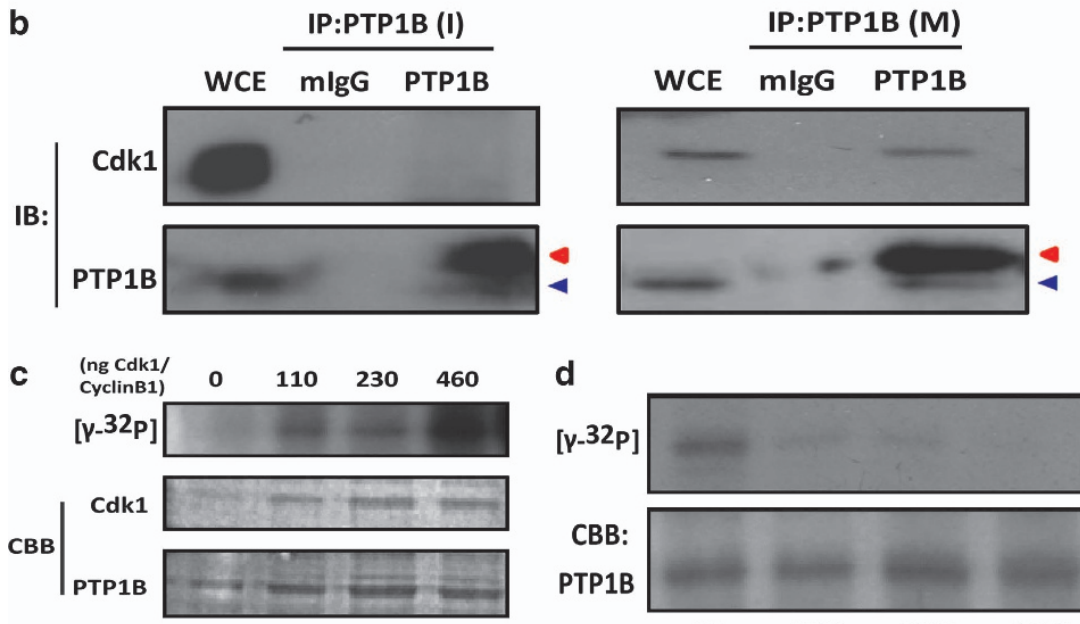

d
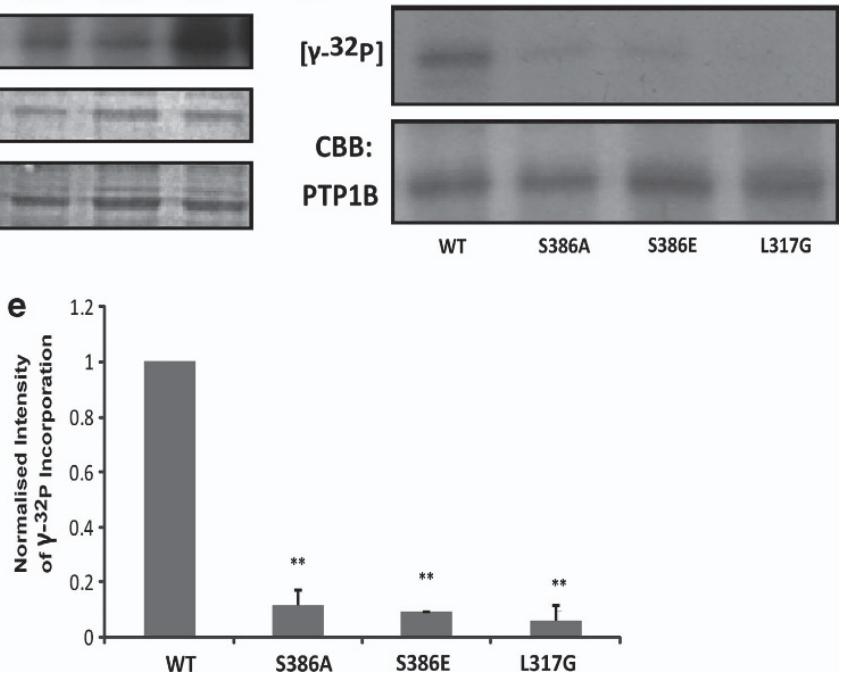

Figure 2 Cdk1 co-immunoprecipitates with PTP1B and phosphorylates it at serine 386. (a) K562 cells were synchronised at the G1/S border using a double thymidine block. At $1 \mathrm{~h}$ post-release, cells were treated with DMSO $(0.1 \% \mathrm{v} / \mathrm{v})$ or Taxol $(\mathrm{TAX})(1 \mu \mathrm{M})$ in the absence or presence of BI2536 (BI) $(20 \mu \mathrm{M}), \mathrm{CK} 2 \mathrm{inhibitor}(\mathrm{CK})(20 \mu \mathrm{M})$ or RO-3306 (RO) $(9 \mu \mathrm{M})$ for a $2 \mathrm{~h}$ period beginning at 8,9 or $10 \mathrm{~h}$ post-thymidine release. Protein was resolved by SDS-PAGE and probed with PTP1B, Bim, BubR1, and GAPDH antibodies. (b) PTP1B was immunoprecipitated from either untreated interphase (I) or mitotically-synchronised (M) K562 cells. Protein was resolved by SDS-PAGE and probed with anti-Cdk1 antibody. A portion (10\%) was retained and probed with PTP1B to confirm immunoprecipitation. Blue arrow indicates PTP1B protein, red arrow indicates antibody heavy chain. (c) Purified recombinant WT-PTP1B-His (500 ng) was incubated with increasing amounts of recombinant Cdk1/cyclin B1 (0-460 ng), $2 \mu \mathrm{Ci}$ of $\left[\gamma_{-}{ }^{32} \mathrm{P}\right]$ ATP, ATP $(100 \mu \mathrm{M})$, at $30{ }^{\circ} \mathrm{C}$ for $1 \mathrm{~h}$. The reaction was terminated by the addition of Laemmli buffer to $1 \times$ concentration. (d) Purified recombinant PTP1B-His (WT, S386A, S386E, and L317G) $(500 \mathrm{ng})$, was incubated with recombinant Cdk1/cyclin B1 $(200 \mathrm{ng})$, ATP $(100 \mu \mathrm{M})$ and $2 \mu \mathrm{Ci}$ of $\left[\gamma-{ }^{32} \mathrm{P}\right]$ ATP for $1 \mathrm{~h}$ at $30^{\circ} \mathrm{C}$. The reaction was terminated by the addition of Laemmli buffer to $1 \times$ concentration. Protein was resolved by SDS-PAGE, and $\left[\gamma_{-}{ }^{32} \mathrm{P}\right]$ incorporation was measured by autoradiography after gel drying. The amount of Plk1 and PTP1B was visualised by CBB staining. (e) Amount of $\left[\gamma^{32} \mathrm{P}\right]$ incorporation in (d) was normalised to WT PTP1B levels and expressed as normalised intensity of $\left[\gamma^{3}{ }^{32} P\right]$ incorporation. Results are representative of the mean \pm S.E.M. of three independent experiments $\left({ }^{*}=P<0.05,{ }^{*}=P<0.01\right.$, using a paired $T$-test $)$

by CBB staining. Analysis of $\gamma_{-}{ }^{32} \mathrm{P}$ incorporation revealed that while Plk1 does not phosphorylate PTP1B in a single kinase assay, it does phosphorylate PTP1B following a priming phosphorylation by Cdk1 (Figure 3d). PTP1B was not phosphorylated when Plk1 was omitted in the second kinase reaction, confirming that the phosphorylation is not due to residual Cdk1 activity (data not shown).
Phosphorylation of PTP1B on serine $\mathbf{3 8 6}$ is essential for PIk1 phosphorylation. We have shown that serine 386 on PTP1B represents a proline-directed Cdk1 phosphorylation site. To determine if phosphorylation on serine 386 is the residue that primes for Plk1 phosphorylation of PTP1B, purified PTP1B protein (WT, S386A and S386E) was incubated with recombinant Plk1 in a single-step kinase 
a

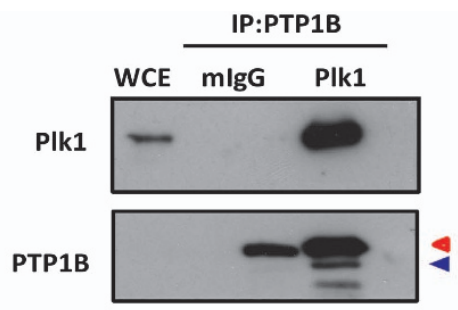

c

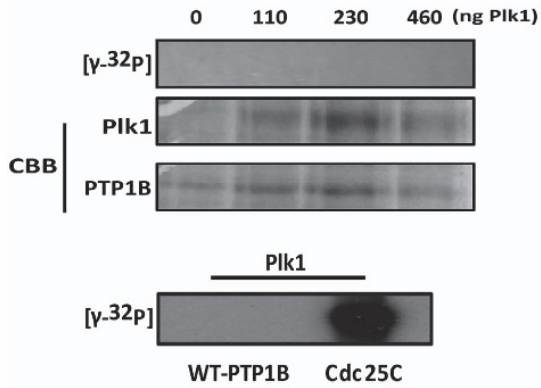

b

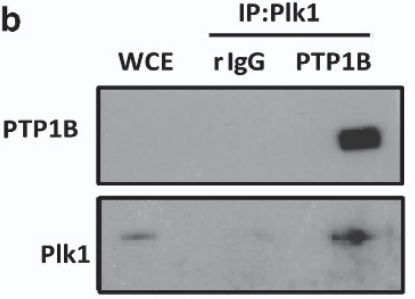

d
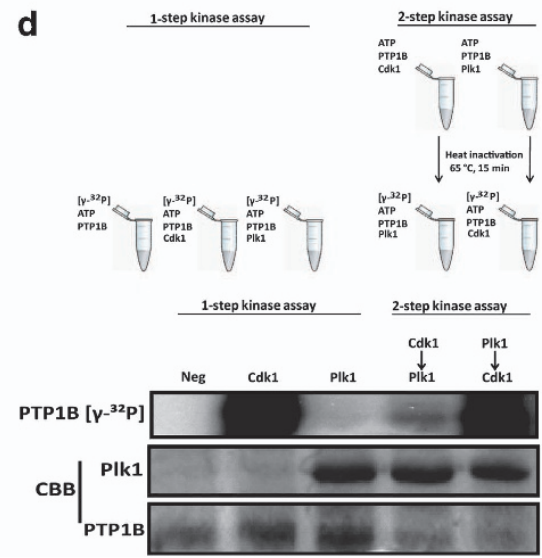

Figure 3 Plk1 phosphorylates PTP1B following a priming phosphorylation by Cdk1. (a) PTP1B and (b) Plk1 were immunoprecipitated from mitotically-synchronised K562 cells. Immunoprecipitated protein was resolved by SDS-PAGE and probed with PIk1 or PTP1B, respectively. In each case a portion of the sample was retained to confirm immunoprecipitation. Blue arrow indicates PTP1B, red arrow indicates antibody heavy chain. (c) Purified recombinant WT-PTP1B-His (500 ng) was incubated with increasing amounts of recombinant Plk1 $(0-460 \mathrm{ng}), 2 \mu \mathrm{Ci}$ of $\left[\gamma^{32}{ }^{32} \mathrm{P}\right] \mathrm{ATP}$, and ATP $(100 \mu \mathrm{M})$, at $30^{\circ} \mathrm{C}$ for $1 \mathrm{~h}$. The reaction was terminated by the addition of Laemmli buffer to $1 \times$ concentration. As a control, Plk1 (460 ng) was incubated with either WT-PTP1B-His ( $500 \mathrm{ng})$ or Cdc25C (500 ng) and $2 \mu \mathrm{Ci}$ of $\left[\gamma_{-}{ }^{32} \mathrm{P}\right]$ ATP, and ATP $(100 \mu \mathrm{M})$, at $30^{\circ} \mathrm{C}$ for $1 \mathrm{~h}$, as before. (d) Purified WT-PTP1B-His (500 ng) was incubated in a one-step kinase assay either alone (NEG) or in the presence of Cdk1 (460 ng) or Plk1 (460 ng) for $1 \mathrm{~h}$ at $30^{\circ} \mathrm{C}$ (lanes 1-3) or pre-incubated with Cdk1 (460 ng) or Plk1 (460 ng) prior to incubation with the alternate kinase, $2 \mu \mathrm{Ci}$ of $\left[\gamma_{-}{ }^{32} \mathrm{P}\right]$ ATP and ATP $(100 \mu \mathrm{M})$ in a two-step kinase assay as outlined (lanes 4-5). The reaction was terminated by the addition of Laemmli buffer. Protein was resolved by SDS-PAGE, and [ $\left.\gamma^{-32} \mathrm{P}\right]$ incorporation was measured by autoradiography after gel drying. The amount of Plk1 and PTP1B was visualised by CBB staining. Results are representative of three independent experiments

assay as before. The WT PTP1B protein and non-phosphorylatable S386A mutant are not phosphorylated by Plk1. However, the phosphomimetic S386E mutant can be phosphorylated by Plk1 (Figure 4a). Cdc25C was included as a positive control. Thus, these data confirm that the phosphorylation of PTP1B by Cdk1 at serine 386 is a necessary and sufficient priming step for the subsequent phosphorylation by Plk1.

PIk1 phosphorylates PTP1B at serine 286 and 393. Plk1 binds to a consensus sequence D/E-X-pS/pT-o-X-D/E, where $O$ is a hydrophobic amino acid. Two consensus sequences have been identified within PTP1B located at residues 283-GDSSVQD-289 and 390-GEPSLPE-396, thus serine 286 and 393 are putative Plk1 phosphorylation sites. To investigate the role of serine 286 and 393 as Plk1 phosphosites, non-phosphorylatable S286A and S393A mutants together with a S286A/S393A double mutant were constructed by site-directed mutagenesis. Purified protein was incubated in a two-step kinase assay, whereby WT PTP1B or the PTP1B mutants were pre-incubated with recombinant Cdk1/cyclin $\mathrm{B} 1$ for $1 \mathrm{~h}$ in a priming reaction followed by incubation with recombinant Plk1 in the second kinase reaction. The amount of $\gamma^{32} \mathrm{P}$ incorporated in WT PTP1B and the three mutants was determined by autoradiography and a representative image is shown in Figure 4b.
Normalised values from triplicate experiments are presented in Figure 4c. In comparison to WT PTP1B, the ability of Plk1 to phosphorylate the S286A and S393A mutants in vitro was greatly reduced. Moreover, the most significant reduction of phosphorylation was detected with the double mutant. This novel data reveals that Plk1 phosphorylates PTP1B at serine 286 and 393, following a priming phosphorylation by Cdk1.

Phosphorylation of PTP1B on serine 286 enhances its phosphatase activity and promotes mitotic cell death. The functional significance of PTP1B phosphorylation on serine 286 and 393 during mitotic arrest was investigated. K562 cells were transfected with empty vector or WT PTP1B, as well as single and double mutants (S286, S393A, S286A/ S393A). Twenty-four hours post transfection, the cells were treated with DMSO, Nocodazole or Taxol $(1 \mu \mathrm{M})$ for $24 \mathrm{~h}$, and the extent of cell death was determined by flow cytometry following propidium iodide staining. The expression of WT and mutant PTP1B was confirmed by western blotting (Figure 5a). Expression of WT PTP1B alone induces cell death in vehicle-treated cells (Figure $5 \mathrm{~b}$ compare Empty and WT), and cell death is potentiated following treatment with Nocodazole (Figure 5c) or Taxol (Figure 5d) for $24 \mathrm{~h}$. Moreover, mutation of the S286 residue abrogates the cell death induced by PTP1B in the absence and presence of Nocodazole or Taxol (Figures 5b-d). However, 

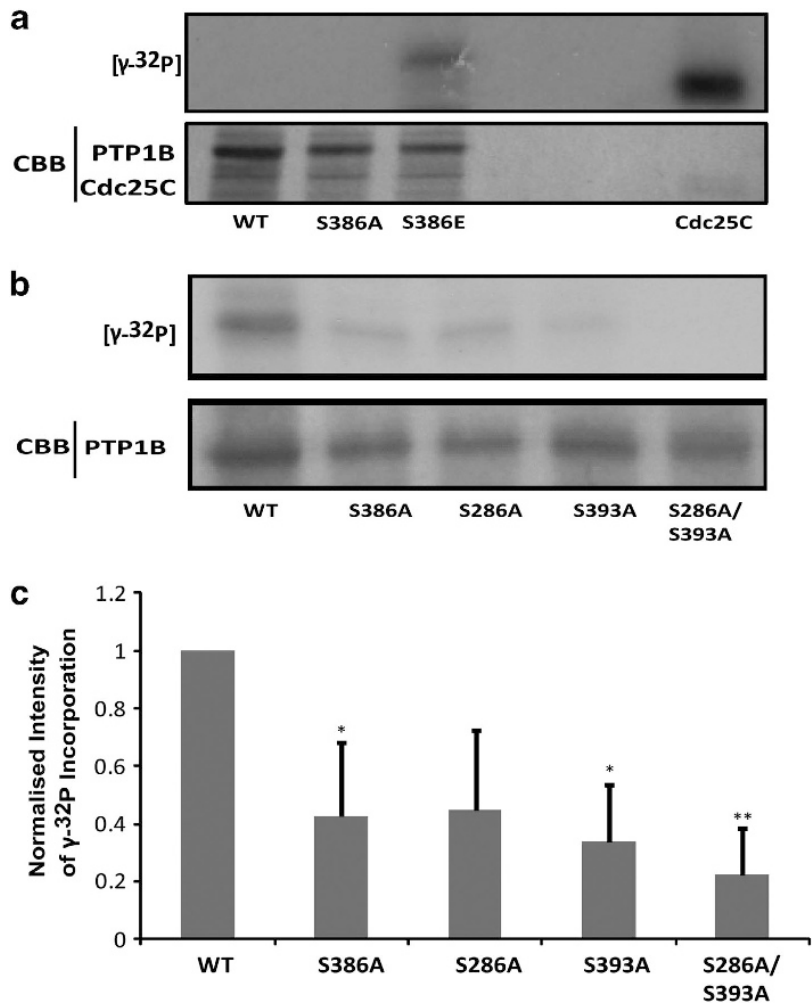

Figure 4 Cdk1-mediated phosphorylation of serine 386 is an essential priming step for Plk1-mediated phosphorylation at serine 286 and 393. (a) Purified recombinant PTP1B-His (WT, S386A, S386E) (500 ng), or Cdc25C (500 ng), was incubated with recombinant Cdk1/cyclin B1 $(200 \mathrm{ng})$, ATP $(100 \mu \mathrm{M})$ and $2 \mu \mathrm{Ci}$ of $\left[\gamma^{32} \mathrm{P}\right]$ ATP for $1 \mathrm{~h}$ at $30^{\circ} \mathrm{C}$. The reaction was terminated by the addition of Laemmli buffer to $1 \times$ concentration. (b) Purified PTP1B-His (WT, or S386A, S286A, S393A, and S286A/S393A mutants) (500 ng) was incubated with ATP $(100 \mu \mathrm{M})$, in the presence of $\mathrm{Cdk} 1(460 \mathrm{ng})$ at $30^{\circ} \mathrm{C}$ for $1 \mathrm{~h}$. The reaction was terminated by incubation at $65^{\circ} \mathrm{C}$ for $15 \mathrm{~min}$. The reaction samples were chilled on ice for $5 \mathrm{~min}$, and then incubated with Plk1 (460 ng), $2 \mu \mathrm{Ci}$ of $\left[\gamma^{32} \mathrm{P}\right]$ ATP and ATP $(100 \mu \mathrm{M})$, for a subsequent kinase reaction at $30^{\circ} \mathrm{C}$ for $1 \mathrm{~h}$. The reaction was terminated by the addition of Laemmli buffer. Protein was resolved by SDS-PAGE, and $\left[\gamma^{32} \mathrm{P}\right]$ incorporation was measured by autoradiography after gel drying. The amount of PTP1B was visualised by CBB staining. (c) The amount of $\left[\gamma^{32} \mathrm{P}\right]$ incorporation was normalised to WT PTP1B levels, and expressed as normalised intensity of $\left[\gamma^{32} \mathrm{P}\right]$ incorporation. Results are representative of the mean \pm S.E.M. of three independent experiments $\left(n=3, \quad{ }^{*}=P<0.05\right.$, ${ }^{* *}=P<0.01$, using a paired $T$-test)

overexpression of the S393A mutant induces cell death in a manner indistinguishable from WT PTP1B. These results reveal that phosphorylation of PTP1B on serine 286 is important for the induction of cell death in K562 cells following prolonged arrest.

Finally, we examined whether the cell death exerted by PTP1B was due to enhanced phosphatase activity. The phosphatase activity of purified WT PTP1B and S286E, S393E, S286E/S393E mutants was determined by substrate dephosphorylation using recombinant Cdc25C as a control. Phosphorylation of PTP1B at serine 286 significantly increases its phosphatase activity, whereas phosphorylation at serine 393 does not (Figure 5e). Overall these results reveal that the phosphorylation of PTP1B on serine 286 is important for PTP1B phosphatase activity and the induction of mitotic cell death.

\section{Discussion}

Mitotic catastrophe is an important mechanism that senses and responds to mitotic failure by driving cells to an irreversible anti-proliferative state through apoptosis, necrosis or senescence. Although the link between mitotic arrest and cell death is well established, details of the molecular mechanisms that bridge these independent processes are only beginning to emerge. ${ }^{1-3}$ MTAs induce mitotic catastrophe that is accompanied by mitotic arrest, and we have previously shown that the cell death induced is accompanied by features of apoptosis including loss of mitochondrial membrane potential and oligonucleosomal DNA fragmentation; however, cell death was not dependent on the activation of caspases. ${ }^{42}$ In this study we provide new insight into the molecular regulation of death following mitotic arrest.

Previous reports have shown that Cdk1 is an important instigator of cell death following mitotic catastrophe by directly phosphorylating cell death substrates. Cdk1 phosphorylates and inactivates pro-survival $\mathrm{Bcl}-2$ proteins, $\mathrm{Bcl}-2, \mathrm{Bcl}-\mathrm{XI}$ and $\mathrm{Mcl}-1$, during prolonged arrest, thus blocking their death inhibitory effects. ${ }^{36,37}$ Furthermore, Cdc2 phosphorylation of the pro-apoptotic $\mathrm{BH} 3$-only protein Bad activates cell death in post-mitotic neurons, ${ }^{38}$ and Cdk1-dependent hyperphosphorylation of Bim on serine 44 is associated with cell death in haematopoietic cells. ${ }^{28}$ The extent of Cdk1 induced phosphorylation of caspase- 2 and caspase- 9 during mitotic arrest also influences the outcome of mitotic catastrophe, although mitotic catastrophe can occur in the absence of caspase activation. ${ }^{39-42}$ Thus, Cdk1 has a key role in balancing survival and cell death signals to dictate cell fate during mitotic arrest. Recent evidence indicates that Plk1 phosphorylation of FADD is required for Taxol-induced death, implicating a second mitotic kinase during mitotic catastrophe. ${ }^{15}$

In this study we provide evidence that the co-operative action of Cdk1 and Plk1 towards the novel substrate PTP1B during mitotic arrest is important for mitotic cell death. PTP1B is phosphorylated in a dose- and time-dependent manner, following treatment of tumour cells with Nocodazole and Taxol. PTP1B phosphorylation correlates with the accumulation of mitotically arrested cells and precedes the onset of mitotic cell death induced by the MTAs. This data correlates with a previous report of PTP1B phosphorylation in HeLa cells following treatment with Nocodazole; however, the functional significance of this phosphorylation was not determined. ${ }^{43}$

We have shown that the phosphorylation of PTP1B is blocked by pharmacological inhibition of Cdk1 and Plk1 during mitosis. It was noted that inhibition of Cdk1 completely blocked PTP1B phosphorylation at all the time points tested, whereas the inhibition of Plk1 only partially blocked PTP1B phosphorylation. This pattern suggests that Cdk1 activity may be a prerequisite for Plk1 activity. The finding that both Cdk1 and Plk1 interact with PTP1B during mitosis, while only Cdk1 directly phosphorylates PTP1B in a single-step kinase assay further supports the hypothesis. Moreover, the finding that pre-incubation of PTP1B with Cdk1 enables the phosphorylation by Plk1 in vitro, confirmed that Plk1 phosphorylation is dependent upon a priming phosphorylation by Cdk1. 

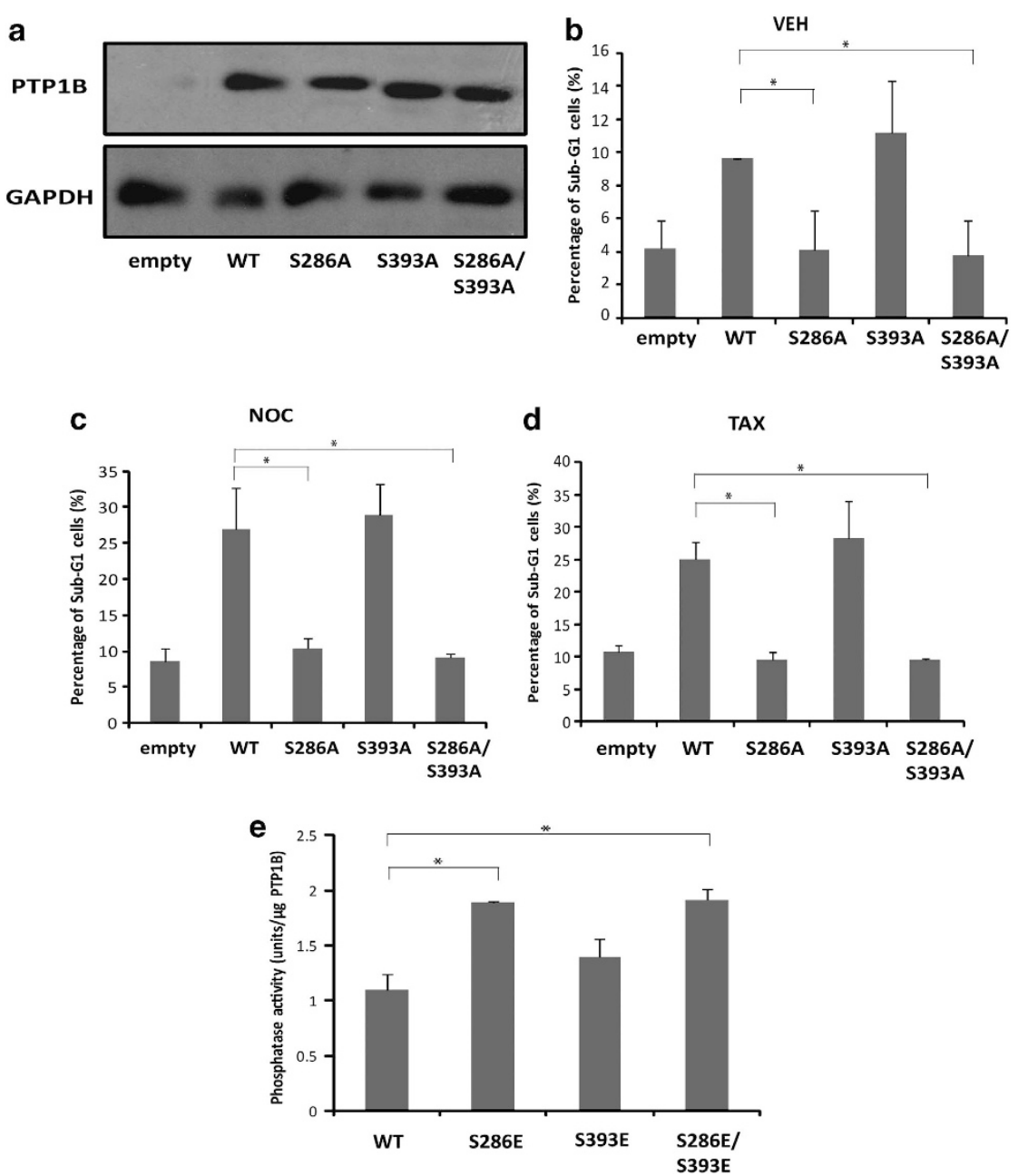

Figure 5 PTP1B phosphorylation regulates mitotic cell death and PTP1B phosphatase activity. K562 cells $\left(1 \times 10^{6}\right)$ were transfected with pEGFP-c1 empty vector $(1 \mu \mathrm{g})$, WT PTP1B-EGFP-c1 $(1 \mu \mathrm{g})$, or S286A, S393A, and S286A/S393A mutants $(1 \mu \mathrm{g})$. Twenty-four hours post-transfection, cells were harvested and WCEs were prepared in RIPA lysis buffer. Equal amounts of protein $(50 \mu \mathrm{g})$ were resolved by SDS-PAGE and probed with anti-PTP1B antibody. Anti-GAPDH was used as a loading control (a). Transfected cells were treated with DMSO (VEH; $0.1 \% \mathrm{v} / \mathrm{v})$, Nocodazole (NOC; $1 \mu \mathrm{M})$ or Taxol (TAX; $(1 \mu \mathrm{M})$ for $24 \mathrm{~h}(\mathrm{~b}-\mathrm{d})$. DNA content was analysed by flow cytometry following propidium iodide staining. Results represent the mean \pm S.E.M. of three independent experiments ( $\left.{ }^{\star} P \leq 0.05\right)$. (e) Purified recombinant PTP1B (WT, S286E, S393E, and S286E/S393E) $(500 \mathrm{ng})$, were diluted $1: 1$ in phosphatase reaction buffer and incubated in duplicate with a well-coated poly-(Glu, pTyr) substrate for $1 \mathrm{~h}$ at $37^{\circ} \mathrm{C}$. Dephosphorylation of substrate was measured by incubation with an anti-pTyr antibody conjugated to HRP enzyme for 30 min at $37^{\circ} \mathrm{C}$, followed by reaction with the colorimetric HRP substrate TMBZ. The HRP reaction was stopped after 15 min incubation at $37^{\circ} \mathrm{C}$, by the addition of $6 \mathrm{~N} \mathrm{H}_{2} \mathrm{SO}_{4}$, and absorbance at $450 \mathrm{~nm}$ was measured. Absorbance values were normalised to units of phosphatase activity by comparison against the standard curve, and results were expressed as units/ $\mu$ g of PTP1B. Results represent the mean \pm S.E.M. of three independent experiments $\left({ }^{*} P \leq 0.05\right)$

The discovery that PTP1B is localised to the ER and mitochondria in K562 cells is in agreement with previous reports that PTP1B is localised at the outer surface of the $\mathrm{ER}^{29}$ and at the mitochondria in rat brain cells, where it participates in src regulation. ${ }^{30}$ Our finding that PTP1B phosphorylation was completely blocked in cell extracts prepared following Cdk1 inhibition, suggests that Cdk1 does not discriminate between ER and mitochondrial pools of PTP1B. Many proteins including pro- and anti-apoptotic $\mathrm{Bcl}-2$ proteins are found at the mitochondrion and the ER and facilitate crosstalk between the two compartments during ER-stress-induced apoptosis..4,45 Furthermore, the ER and mitochondrial outer membranes are contiguous via a region termed the mitochondria-associated ER membrane, and recent studies suggest that contacts between the mitochondria and ER can propagate cellular signals by the transfer of calcium and lipids between the organelles. ${ }^{46,47}$

Analysis of the PTP1B sequence revealed the presence of a putative proline-directed serine/threonine phosphorylation site at serine 386 and a cyclin-binding motif, together with two Plk1 phosphorylation sites at serine 286 and 393. In this study it was found that non-phosphorylatable or phosphomimetic S386 mutants are unable to accept a free phosphate group in vitro. In addition, mutation of the cyclin-binding site at L317 within PTP1B abrogates Cdk1-mediated phosphorylation in vitro. Mutation of either of the two Plk1 phosphosites (serine 286 and 393) to a non-phosphorylatable form significantly reduced PTP1B phosphorylation, following 
Cdk1 priming and almost complete inhibition was achieved with the S286/S393 double mutant, indicating that Plk1 phosphorylates PTP1B at these two sites, following a priming phosphorylation by Cdk1. Moreover, the PTP1B S386E phosphomimetic mutant was sufficient to allow Plk1 phosphorylation of PTP1B in the absence of a priming incubation with $\mathrm{Cdk} 1$, thereby confirming the priming role of phosphorylated serine 386 .

This data is in agreement with other reports where Cdk1-dependent phosphorylation acts as a crucial priming step for Plk1 phosphorylation. Examples include the mitotic regulators BubR1 and FoxM1, ${ }^{31,32}$ the centrosome proteins Cep55 and Nedd $1^{33,34}$ and the filament protein vimentin. $^{35}$ Thus, we add PTP1B to the list of proteins that undergo phosphorylation by the co-operative action of $\mathrm{Cdk} 1$ and Plk1.

To date, investigations into the role of phosphatases in mitotic cell death signalling have focused on the serine/ threonine phosphatases, namely PP1 and PP2A that antagonise Cdk1 activity and dephosphorylate cell death substrates. $^{48,49}$ We hypothesised that the co-ordinate phosphorylation and regulation of PTP1B by two major mitotic kinases may serve as an important regulator of cell survival and cell death signals. In support of this, it was found that overexpression of WT PTP1B is sufficient to induce cell death in $\mathrm{K} 562$ cells, which is the first such report in human tumour cells and is consistent with reports in immortalised murine adipocytes and hepatocytes. ${ }^{17,20}$ Furthermore, cell death induced by WT PTP1B was potentiated in the presence of Taxol and Nocodazole. The role of phosphorylated serine 286 and 393 in the induction of cell death was investigated. The unphosphorylatable S286A mutant abrogated cell death induced by PTP1B expression, whereas the S393A mutant induced cell death to a similar level as WT PTP1B. Furthermore, while the expression of WT PTP1B sensitised K562 cells to MTA-induced death as discussed earlier, this was reversed by overexpression of the S286A mutant, but not the S393 mutant. Collectively, this data reveals the importance of phosphorylated serine 286 in cell death induced by PTP1B following failed mitosis.

The effect of serine 286 phosphorylation on PTP1B phosphatase activity was investigated, and it is shown that phosphorylation of serine 286 increases its phosphatase activity, whereas phosphorylation of serine 393 does not. Thus, this study reveals that the co-ordinate action of Cdk1 and Plk1 during mitotic arrest promotes mitotic cell death by the direct phosphorylation and activation of the tyrosine phosphatase PTP1B. It is possible that phosphorylation on serine 286 induces a conformational change in PTP1B that facilitates the interaction and dephosphorylation of downstream substrates to elicit mitotic cell death. Additional studies to identify cell death-specific PTP1B substrates will provide important insight into its death promoting activity.

PTP1B exerts both oncogenic and tumour-suppressive effects, which has been attributed to genetic and epigenetic modifications within the PTP genes. ${ }^{50}$ We demonstrate a post translational mechanism that enhances PTP1B phosphatase activity and tumour-suppressive action in tumour cells. The localisation of PTP1B to the ER and mitochondrion positions it as a potential mediator of numerous cell death signals as well as potential roles in the regulation of redox metabolism. This study also reveals that phosphorylation of PTP1B on serine 393 does not promote its phosphatase activity and is not required for $\mathrm{PTP} 1 \mathrm{~B}-\mathrm{mediated}$ cell death. It is possible that phosphorylation on serine 393 is important in the antiapoptotic function of PTP1B. Thus, the discrete phosphorylation signature described in this study provides a molecular understanding of the paradoxical roles of PTP1B in tumourigenesis.

\section{Materials and Methods}

Antibodies and recombinant proteins. All commercial antibodies were purchased from the following; secondary anti-mouse and anti-rabbit HRPconjugated secondary antibodies (Cell Signaling Technology, Inc., Danvers, MA, USA); anti-Bim antibody (Alpha Technologies Ltd., Wicklow, Ireland); anti-PTP1B and anti-BubR1 antibodies (BD Biosciences, Franklin Lakes, NJ, USA); antiMnSOD antibody (Enzo Life Sciences (UK) Ltd., Exeter, UK); anti-Cdk1 antibody and anti-PIk1 antibodies (Santa Cruz Biotechnology Inc., Heidelberg, Germany), anti-GAPDH antibody (Millipore Corporation, Billerica, MA, USA). The active kinases Cdk1/cyclin B and Plk1 were purchased from Millipore Ireland, and Cdc25C phosphatase was purchased from Enzo Life Sciences.

Plasmid production. Full-length PTP1B was amplified by standard PCR methods and sub-cloned into either the pEGFP-c1 vector (Clontech-Takara Bio Europe, Saint-Germain-en-Laye, France), or the pRSET-C 6xHis-tag vector (Invitrogen, Carlsbad, CA, USA). Mutant PTP1B-GFP and PTP1B-His constructs were created from these templates using a Quik change kit, as directed by the manufacturer (Stratagene, La Jolla, CA, USA).

Cell culture, treatment and transfection. K562 and KYO1 chronic myelogenous leukemia cells were grown in suspension in RPMI 1640 medium supplemented with $2 \mathrm{mM}$ L-glutamine, penicillin $(100 \mu \mathrm{g} / \mathrm{ml})$, streptomycin $(100 \mu \mathrm{g} / \mathrm{ml})$ and foetal bovine serum $(10 \%(\mathrm{v} / \mathrm{v}))$. Cells were incubated at $37^{\circ} \mathrm{C}$, with $\mathrm{CO}_{2}(5 \%)$ and $\mathrm{O}_{2}(95 \%)$. K562 cells were transfected with PTP1BpEGFP-c1 vector and mutants, using the Nucleofector II 96-well shuttle system (Lonza Group Ltd., Basel, Switzerland), as directed by the manufacturer. All drug stocks were prepared in $100 \%$ DMSO, and unless otherwise stated cells were treated with the following reagents at the indicated concentrations; DMSO $(0.1 \% \mathrm{v} /$ v), nocodazole $(1 \mu \mathrm{M})$, taxol $(1 \mu \mathrm{M})$, Bl2536 $(20 \mu \mathrm{M})$, RO-3306 $(9 \mu \mathrm{M})$, CK2 inhibitor II $(20 \mu \mathrm{M})$, for the indicated time points.

Immunoblot analysis and immunoprecipitation. After treating with different conditions as described in the figures 1, 2 and 5 legends, the cells were lysed in RIPA buffer (20 mM Tris, pH 7.6, 0.5\% NP-40, $250 \mathrm{mM} \mathrm{NaCl}, 3 \mathrm{mM}$ EDTA, $3 \mathrm{mM}$ EGTA, $2 \mathrm{mM}$ dithiothreitol, $0.5 \mathrm{mM}$ PMSF, $20 \mathrm{mM} \beta$-glycerophosphate, $1 \mathrm{mM}$ sodium orthovanadate, and $1 \mathrm{mg} / \mathrm{ml}$ leupeptin). For immunoblots, $50 \mu \mathrm{g}$ of the lysates was fractionated by SDS-PAGE, probed by western blotting with the relevant antibody, and visualised by enhanced chemiluminescence (Thermo Fisher Scientific, Waltham, MA, USA).

For immunoprecipitation assays, the cells were collected in RIPA buffer after treatments as described in the figures 2 and 3 legends. An amount of $1.5 \mathrm{mg}$ of protein from the resulting lysates was precipitated with $2 \mu \mathrm{g}$ of the relevant antibody and protein $\mathrm{A} / \mathrm{G}$-sepharose beads by incubation at $4{ }^{\circ} \mathrm{C}$ overnight. Immunoprecipitates were washed three times with RIPA buffer and the bound proteins were resolved in 10\% SDS-PAGE gels for immunoblot analysis with the relevant antibodies.

Recombinant protein production and purification. PTP1B-pRSET$C$ plasmid construct and mutants was transformed into SoluBL21 Escherichia coli (Amsbio, Lake Forest, CA, USA), and heterologous protein expression was induced by culture in auto-induction medium (Formedium, Norfolk, UK), at $37^{\circ} \mathrm{C}$ for $24 \mathrm{~h}$. Recombinant PTP1B-His protein was solubilised in sarkosyl lysis buffer (50 mM Tris, $300 \mathrm{mM} \mathrm{NaCl}, 5 \mathrm{mM} \mathrm{ZnCl}_{2}, 1 \%$ sarkosyl, 2\% Triton X-100 and $20 \mathrm{mM}$ CHAPS), and purified using HisPur Ni-NTA column, by elution in $100 \mathrm{mM}$ imidazole in PBS, as directed by manufacturer (Thermo Fisher Scientific). Imidazole was removed from solutions by dialysis against $3 \times 200 \times$ volumes of PBS, using Slide-a-Lyzer dialysis cassettes (Thermo Fisher Scientific) 
In vitro kinase assay. Kinase assays were set up by adding $500 \mathrm{ng}$ PTP1BHis (WT or mutants) to kinase reaction buffer (50 mM HEPES, pH 7.5, $10 \mathrm{mM}$ $\mathrm{MgCl}_{2}, 2.5 \mathrm{mM}$ EGTA, $0.1 \mathrm{mM}$ dithiothreitol, and $0.1 \mathrm{mM}$ sodium orthovanadate) containing ATP $(100 \mu \mathrm{M}), 2 \mu \mathrm{Ci}$ of $\left[\gamma^{32} \mathrm{P}\right]$ ATP and recombinant Cdk1/cyclin B or Plk1 kinases (110-460 $\mathrm{ng}$ ) for $1 \mathrm{~h}$ at $30^{\circ} \mathrm{C}$. The reaction was stopped by adding Laemmli buffer to $1 \times$ concentration, and protein was resolved by SDS-PAGE and visualised by staining with CBB. The incorporation of $\left[\gamma^{32} \mathrm{P}\right]$ ATP was visualised by exposure to X-ray film for at least $24 \mathrm{~h}$ at $-80^{\circ} \mathrm{C}$.

Determination of cell death. Cells were harvested by centrifugation and fixed in ice-cold ethanol $(70 \% \mathrm{v} / \mathrm{v})$ at $4{ }^{\circ} \mathrm{C}$ overnight prior to flow cytometry analysis. Fixed cells were resuspended in PBS containing $1 \mu \mathrm{g} / \mathrm{ml}$ propidium iodide and $30 \mu \mathrm{g} / \mathrm{ml} \mathrm{RNAse} \mathrm{A}$, incubated at $37^{\circ} \mathrm{C}$ for $1 \mathrm{~h}$, and analysed using the Cyan ADP flow cytometer (Beckman Coulter Inc., Brea, CA, USA).

Fluorescent imaging. K562 cells were transfected with PTP1B-pEGFP-c1 plasmid, and incubated at $37^{\circ} \mathrm{C}$ for $24 \mathrm{~h}$. Cells were then incubated with $100 \mathrm{nM}$ MitoTracker dye (Invitrogen) for $10 \mathrm{~min}$ before cytocentrifugation onto a glass slide. Cells were then stained with DAPI $(1 \mu \mathrm{g} / \mathrm{ml})$ for $20 \mathrm{~s}$, and washed in PBS. Coverslips were affixed with fluorescent mounting medium (Dako, Glostrup, Denmark), and cells were visualised using the Axiolmager 2 fluorescent microscope (Zeiss, Oberkochen, Germany).

Phosphatase assay. Purified recombinant PTP1B-His and phosphomimetic mutants (PTP1B-His S286E, S393E, S286E/S393E) were examined for altered phosphatase activity, using an in vitro, colorimetric assay of substrate dephosphorylation (Takara Bio Inc., Shiga, Japan) and recombinant Cdc25C phosphatase as a standard.

\section{Conflict of Interest}

The authors declare no conflict of interest.

Acknowledgements. This work was supported by Science Foundation Ireland research frontiers programme.

1. Vitale I, Galluzzi L, Castedo M, Kroemer G. Mitotic catastrophe: a mechanism for avoiding genomic instability. Nat Rev Mol Cell Biol 2011; 12: 385-392.

2. Galluzzi L, Vitale I, Abrams J, Alnemri E, Baehrecke E, Blagosklonny M et al. Molecular definitions of cell death subroutines: recommendations of the Nomenclature Committee on Cell Death 2012. Cell Death Differ 2012; 19: 107-120.

3. Eom Y-W, Kim MA, Park SS, Goo MJ, Kwon HJ, Sohn S et al. Two distinct modes of cell death induced by doxorubicin: apoptosis and cell death through mitotic catastrophe accompanied by senescence-like phenotype. Oncogene 2005; 24: 4765-4777.

4. Manchado E, Guillamot M, Malumbres M. Killing cells by targeting mitosis. Cell Death Differ 2012; 19: 369-377.

5. Nigg EA. Mitotic kinases as regulators of cell division and its checkpoints. Nat Rev Mol Cell Biol 2001; 2: 21-32

6. Donaldson MM, Tavares AAM, Hagan IM, Nigg EA, Glover DM. The mitotic roles of Pololike kinase. J Cell Sci 2001; 114: 2357-2358.

7. Petronczki M, Lenart P, Peters J-M. Polo on the rise: from mitotic entry to cytokinesis with Plk1. Dev Cell 2008; 14: 646-659.

8. Elia AE, Rellos P, Haire LF, Chao JW, Ivins FJ, Hoepker K et al. The molecular basis for phosphodependent substrate targeting and regulation of Plks by the Polo-box domain. Cell 2003; 115: 83-95.

9. Knecht R, Elez R, Oechler M, Solbach C, Cv llberg, Strebhardt K. Prognostic significance of polo-like kinase (PLK) expression in squamous cell carcinomas of the head and neck. Cancer Res 1999; 59: 2794-2797

10. Wolf G, Elez R, Doermer A, Holtrich U, Ackermann H, Stutte HJ et al. Prognostic significance of polo-like kinase (PLK) expression in non-small cell lung cancer. Oncogene 1997; 14: 543.

11. Bu Y, Yang Z, Li Q, Song F. Silencing of polo-like kinase (PIk) 1 via siRNA causes inhibition of growth and induction of apoptosis in human esophageal cancer cells. Oncology 2008 ; 74: 198-206.

12. Schmit TL, Zhong W, Setaluri V, Spiegelman VS, Ahmad N. Targeted depletion of Polo-like kinase (Plk) 1 through lentiviral shRNA or a small-molecule inhibitor causes mitotic catastrophe and induction of apoptosis in human melanoma cells. J Invest Dermatol 2009, 129: 2843-2853.
13. Conn CW, Hennigan RF, Dai W, Sanchez Y, Stambrook PJ. Incomplete Cytokinesis and Induction of Apoptosis by Overexpression of the Mammalian Polo-Like Kinase, Plk3. Cancer Res 2000; 60: 6826-6831.

14. Mundt K, Golsteyn R, Lane H, Nigg E. On the regulation and function of human polo-like kinase 1 (PLK1): effects of overexpression on cell cycle progression. Biochem Biophys Res Commun 1997; 239: 377-385.

15. Jang MS, Lee SJ, Kim CJ, Lee CW, Kim E. Phosphorylation by polo-like kinase 1 induces the tumor-suppressing activity of FADD. Oncogene 2011; 30: 471-481.

16. Hoekstra E, Peppelenbosch MP, Fuhler GM. The role of protein tyrosine phosphatases in colorectal cancer. Biochim Biophys Acta 2012; 1826: 179-188

17. Gonzalez-Rodriguez A, Escribano O, Alba J, Rondinone CM, Benito M, Valverde AM. Levels of protein tyrosine phosphatase $1 B$ determine susceptibility to apoptosis in serumdeprived hepatocytes. J Cell Physiol 2007; 212: 76-88.

18. Song $H$, Zhang $Z$, Wang $L$. Small interference RNA against PTP-1B reduces hypoxia/ reoxygenation induced apoptosis of rat cardiomyocytes. Apoptosis 2008; 13: 383-393.

19. Lu X, Chen J, Sasmono RT, Hsi ED, Sarosiek KA, Tiganis T et al. T-cell protein tyrosine phosphatase, distinctively expressed in activated-B-cell-like diffuse large B-cell lymphomas, is the nuclear phosphatase of STAT6. Mol Cell Biol 2007; 27: 2166-2179.

20. Miranda S, González-Rodríguez Á, Revuelta-Cervantes J, Rondinone CM, Valverde ÁM. Beneficial effects of PTP1B deficiency on brown adipocyte differentiation and protection against apoptosis induced by pro- and anti-inflammatory stimuli. Cell Signal 2010; 22: $645-659$.

21. Bjorge JD, Pang A, Fujita DJ. Identification of protein-tyrosine phosphatase $1 \mathrm{~B}$ as the major tyrosine phosphatase activity capable of dephosphorylating and activating c-src in several human breast cancer cell lines. J Biol Chem 2000; 275: 41439-41446.

22. Dubé N, Tremblay ML. Beyond the metabolic function of PTP1B. Cell Cycle 2004; 3: 550-553.

23. Bentires-Alj M, Neel BG. Protein-tyrosine phosphatase 1B is required for HER2/Neuinduced breast cancer. Cancer Res 2007; 67: 2420-2424.

24. LaMontagne KR, Flint AJ, Franza BR, Pendergast AM, Tonks NK. Protein tyrosine phosphatase $1 \mathrm{~B}$ antagonizes signalling by oncoprotein tyrosine kinase $\mathrm{p} 210 \mathrm{bcr}$-abl in vivo. Mol Cell Biol 1998; 18: 2965-2975.

25. Koyama N, Koschmieder S, Tyagi S, Portero-Robles I, Chromic J, Myloch S et al. Inhibition of phosphotyrosine phosphatase $1 \mathrm{~B}$ causes resistance in BCR-ABL-positive leukemia cells to the ABL kinase inhibitor STI571. Clin Cancer Res 2006; 12: 2025-2031.

26. Alvira D, Naughton R, Bhatt L, Tedesco S, Landry WD, Cotter TG. Inhibition of proteintyrosine phosphatase 1B (PTP1B) mediates ubiquitination and degradation of Bcr-Abl protein. J Biol Chem 2011; 286: 32313-32323.

27. Jordan MA, Wilson L. Microtubules as a target for anticancer drugs. Nat Rev Cancer 2004; 4: 253-265.

28. Mac Fhearraigh S, Mc Gee MM. Cyclin B1 interacts with the BH3-only protein Bim and mediates its phosphorylation by Cdk1 during mitosis. Cell cycle 2011; 10: 22.

29. Frangioni JV, Oda A, Smith M, Salzman EW, Neel BG. Calpain-catalyzed cleavage and subcellular relocation of protein phosphotyrosine phosphatase 1B (PTP-1B) in human platelets. EMBO J 1993; 12: 4843

30. Arachiche A, Augereau O, Decossas M, Pertuiset C, Gontier E, Letellier T et al. Localization of PTP-1B, SHP-2, and Src exclusively in rat brain mitochondria and functional consequences. J Biol Chem 2008; 283: 24406-24411.

31. Wong OK, Fang G. Cdk1 phosphorylation of BubR1 controls spindle checkpoint arrest and Plk1-mediated formation of the 3F3/2 epitope. J Cell Biol 2007; 179: 611-617.

32. Fu Z, Malureanu L, Huang J, Wang W, Li H, van Deursen JM et al. Plk1-dependent phosphorylation of FoxM1 regulates a transcriptional programme required for mitotic progression. Nat Cell Biol 2008; 10: 1076-1082.

33. Fabbro M, Zhou BB, Takahashi M, Sarcevic B, Lal P, Graham ME et al. Cdk1/Erk2-and Plk1-dependent phosphorylation of a centrosome protein, Cep55, is required for its recruitment to midbody and cytokinesis. Dev Cell 2005; 9: 477-488.

34. Zhang X, Chen Q, Feng J, Hou J, Yang F, Liu J et al. Sequential phosphorylation of Nedd 1 by $\mathrm{Cdk} 1$ and Plk1 is required for targeting of the $\gamma$ TuRC to the centrosome. J Cell Sci 2009; 122: 2240-2251.

35. Yamaguchi T, Goto H, Yokoyama T, Silljé H, Hanisch A, Uldschmid A et al. Phosphorylation by Cdk1 induces Plk1-mediated vimentin phosphorylation during mitosis. J Cell Biol 2005; 171: 431-436.

36. Terrano DT, Upreti M, Chambers TC. Cyclin-dependent kinase 1-mediated Bcl-xL/Bcl-2 phosphorylation acts as a functional link coupling mitotic arrest and apoptosis. Mol Cell Biol 2010; 30: 640-656.

37. Harley ME, Allan LA, Sanderson HS, Clarke PR. Phosphorylation of Mcl-1 by CDK1-cyclin B1 initiates its Cdc20-dependent destruction during mitotic arrest. EMBO J 2010; 29: 2407-2420.

38. Konishi $Y$, Lehtinen M, Donovan N, Bonni A. Cdc2 phosphorylation of BAD links the cell cycle to the cell death machinery. Mol Cell 2002; 9: 1005-1016.

39. Andersen JL, Johnson CE, Freel CD, Parrish AB, Day JL, Buchakjian MR et al. Restraint of apoptosis during mitosis through interdomain phosphorylation of caspase-2. EMBO J 2009; 28: 3216-3227

40. Allan LA, Clarke PR. Phosphorylation of caspase- 9 by CDK1/cyclin B1 protects mitotic cells against apoptosis. Mol Cell 2007; 26: 301-310. 
41. Mansilla S, Priebe W, Portugal J. Brief report mitotic catastrophe results in cell death by caspase-dependent and caspase-independent mechanisms. Cell Cycle 2006; 5 : 53-60.

42. McGrath LB, Onnis V, Campiani G, Williams DC, Zisterer DM, Mc Gee MM. Caspaseactivated DNase (CAD)-independent oligonucleosomal DNA fragmentation in chronic myeloid leukaemia cells; a requirement for serine protease and $\mathrm{Mn} 2+$-dependent acidic endonuclease activity. Apoptosis 2006; 11: 1473-1487.

43. Flint AJ, Gebbink MF, Franza BR Jr., Hill DE, Tonks NK. Multi-site phosphorylation of the protein tyrosine phosphatase, PTP1B: identification of cell cycle regulated and phorbol ester stimulated sites of phosphorylation. EMBO J 1993; 12: 1937-1946.

44. Rong Y, Distelhorst CW. Bcl-2 protein family members: versatile regulators of calcium signaling in cell survival and apoptosis. Annu Rev Physiol 2008; 70: 73-91.

45. Morishima N, Nakanishi K, Tsuchiya K, Shibata T, Seiwa E. Translocation of $\mathrm{Bim}$ to the endoplasmic reticulum (ER) mediates ER stress signaling for activation of Caspase-12 during ER stress-induced apoptosis. J Biol Chem 2004; 279: 50375-50381.

46. De Brito OM, Scorrano L. Mitofusin 2 tethers endoplasmic reticulum to mitochondria. Nature 2008; 456: 605-610.
47. Chipuk Jerry E, McStay Gavin P, Bharti A, Kuwana T, Clarke Christopher J, Siskind Leah J et al. Sphingolipid metabolism cooperates with BAK and BAX to promote the mitochondrial pathway of apoptosis. Cell 2012; 148: 988-1000.

48. Ayllon V, Martinez-A C, Garcia A, Cayla X, Rebollo A. Protein phosphatase 1[alpha] is a Ras-activated Bad phosphatase that regulates interleukin-2 deprivation-induced apoptosis. EMBO J 2000; 19: 2237-2246.

49. Manchado E, Guillamot M, de Cárcer G, Eguren M, Trickey M, García-Higuera I et al. Targeting mitotic exit leads to tumor regression in vivo: modulation by Cdk1, Mastl, and the PP2A/B55 $\alpha, \delta$ phosphatase. Cancer Cell 2010; 18: 641-654.

50. Julien SG, Dube N, Hardy S, Tremblay ML. Inside the human cancer tyrosine phosphatome. Nat Rev Cancer 2011; 11: 35-49.

Cell Death and Disease is an open-access journal published by Nature Publishing Group. This work is licensed under the Creative Commons Attribution-NonCommercial-No Derivative Works 3.0 Unported License. To view a copy of this license, visit http://creativecommons.org/licenses/by-nc-nd/3.0/ 